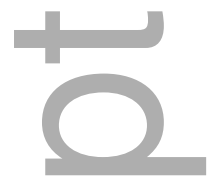

Article type : Research Article

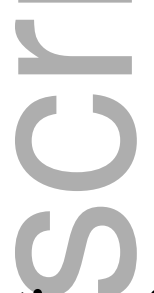

\title{
Validation of Questionnaire and Diary Measures of Time Outdoors Against an Objective Measure of Personal Ultraviolet Radiation

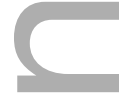 \\ Exposure
}

Anne E Cust ${ }^{*}{ }^{1,2}$, Georgina L Fenton ${ }^{1}$, Amelia K Smit ${ }^{1}$, David Espinoza ${ }^{3}$, Suzanne

Dobbinson ${ }^{4}$, Alison Brodie ${ }^{5}$, Huong Tran Cam Dang ${ }^{5}$, Michael G Kimlin ${ }^{5,6}$

${ }^{1}$ Cancer Epidemiology and Prevention Research, Sydney School of Public Health, The

University of Sydney, Australia,

${ }^{2}$ Melanoma Institute Australia, The University of Sydney, Sydney, Australia

${ }^{3}$ NHMRC Clinical Trials Centre, The University of Sydney, Sydney, Australia

${ }^{4}$ Cancer Council Victoria, Melbourne, Australia

${ }^{5}$ The University of the Sunshine Coast, Maroochydore, Australia

${ }^{6}$ Cancer Council Queensland, Brisbane, Australia

*Corresponding author's email: anne.cust@ sydney.edu.au (Anne Cust)

This is the author manuscript accepted for publication and has undergone full peer review but has not been through the copyediting, typesetting, pagination and proofreading process, which may lead to differences between this version and the Version of Record. Please cite this article as doi: $\underline{10.1111 / \text { php.12893 }}$

This article is protected by copyright. All rights reserved 


\section{ABSTRACT}

Self-reported sun exposure is commonly measured using questionnaires or diaries, but there are limited data on their validity, particularly for population subgroups. This research aimed to compare self-reported sun exposure, measured as 1) habitual time outdoors over the past month on weekends and weekdays, and 2) a four-day diary measure, against objective measurement of personal ultraviolet radiation using polysulfone film dosimeters. From November 2015 to January 2016, 94 people (22-69 years and living in New South Wales, Australia) completed a questionnaire, 4-day diary and 4-day dosimeter measures of overall, weekday and weekend sun exposure. Spearman correlations and Bland-Altman plots were used to measure agreement. The overall weekly correlation was 0.57 (95\% confidence interval [CI] 0.44, 0.68) between standard erythemal doses (SEDs) measured by dosimeter and time spent outdoors measured by questionnaire, 0.74 (95\% CI 0.66-0.81) between dosimeter and diary, and 0.59 (95\% CI 0.480.68) between questionnaire and diary measures. Validity was lower for younger people and weekend sun exposure. There was strong correlation between dosimeter and sun diary measures and moderate correlation between dosimeter and questionnaire measures. Daily measurement over a longer period may be required to accurately capture week-long sun exposure in all population subgroups.

\section{INTRODUCTION}

Melanoma research relies heavily on assessment of sun exposure and requires valid and reliable measures to quantify levels of personal exposure to ultraviolet (UV) radiation. Self-reported sun exposure is routinely used to quantify exposure in epidemiological studies because this approach is feasible for large population samples (1). Biological measures of UV exposure correlate well with self-reported long-term cumulative sun exposure (2-4), and there has been increasing attempts to assess the validity of self-reported measures of sun exposure for shorter time-periods using objective measures (5-11).

UV dosimeters provide an objective measure of personal UV exposure allowing comparisons with self-reported measures. UV dosimeters are non-invasive, portable, and have generally been 
used in small-scale studies over short periods of time (1) due to noncompliance and costs associated with long-term monitoring (12). A number of studies have examined the association between self-reported sun exposure measures and personal UV dosimetry with inconsistent correlations reported $(5,6,9-11,13-16)$. There is variation in the sun exposure measures that have been analysed in the literature. Some studies have used questionnaire data collection methods capturing habitual exposure over weeks or years. Other studies have used more detailed self-reported data from sun diaries, which generally capture more detailed exposure over several days or one-week $(1,11)$.

The aim of this study was to compare self-reported sun exposure, measured as 1) habitual time outdoors over the past month on weekends and weekdays, and 2) a four-day diary measure, against objective measurement of UV radiation using polysulfone film dosimeters. The results from this study are relevant to future epidemiological studies exploring the relationship between sun exposure and health outcomes.

\section{MATERIALS AND METHODS}

Study design and recruitment. The data for this analysis were derived from a pilot randomized controlled trial, for which the design, methods and main behavioural results have been previously reported (17). Figure 1 shows the study flowchart. Participants in the study were from the general population and recruited from the Cancer Council New South Wales (NSW), "Join a Research Study" database, comprising individuals who have agreed to be contacted for ethically-approved cancer research studies. Individuals eligible for recruitment into the pilot trial were aged 18-69 years, had no personal history of melanoma, were residing in the state of NSW, Australia and had sufficient English language abilities to complete questionnaires. Ethics approval was obtained from The University of Sydney and all participants provided informed consent.

A total of 118 invitees consented to participate in the pilot trial (41\% consent), provided a DNA sample for genotyping and completed a baseline questionnaire. Participants were randomly allocated to either the intervention, whereby they received information on their personalized 
genomic risk of melanoma, or waitlist control arm (the same intervention delivered at the end of the study). Three months after receiving their genomic risk information, participants were sent a follow-up questionnaire; were asked to wear a UV dosimeter over four days (2 weekdays and 2 weekend days); and to complete a sun diary on the same days as wearing the UV dosimeter.

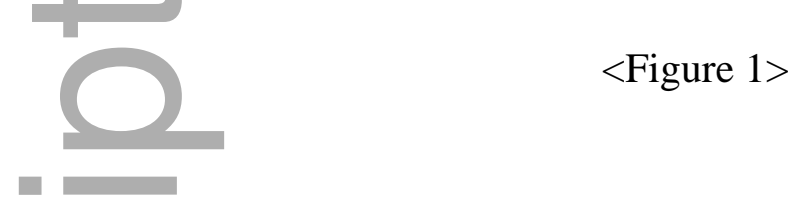

Questionnaire. The 3-month questionnaire included two questions specifically related to time spent outdoors: "Thinking about the past month, we would like to know the times of day as well as the usual length of time that you spend outside between 9am and 5pm on a typical weekday” and "......between 9 am and 5pm on a typical weekend". For both questions, participants recorded the time spent outdoors each hour between $9 \mathrm{am}$ and $5 \mathrm{pm}$ in 15 minute increments, with possible responses: never, less than 15 minutes, 15-29 minutes, 30-44 minutes, 45-60 minutes.

UV Dosimeter. An objective measure of sun exposure was collected at 3-months follow-up using polysulfone film ultraviolet dosimeters, which are considered an objective reference measure of $\operatorname{UVB}(5,13)$. The data were analysed as Standard Erythemal Doses (SEDs), which is a standard measure of UV dose; a person's daily SED exposure is influenced by time of day (i.e. more SEDs per hour in the middle of the day), time in the sun, use of sun protection and season (12). Participants were asked to wear a custom-made wristband with a new dosimeter badge inserted each day, over 2 weekdays and 2 weekend days. The wrist has been shown to be a practical and reliable location for personal UV dosimetry (18).

Sun Diary. Participants completed a sun diary on the same day as they wore the UV dosimeter, recording the time spent outdoors each hour between $5 \mathrm{am}$ and $7 \mathrm{pm}$ in 15 -minute increments, with possible responses: never, less than 15 minutes, 15-29 minutes, 30-44 minutes, 45-60 minutes.

Data Analysis. Agreement between the different measures of sun exposure was assessed using the data collected at 3-months follow-up, in which 108 (92\%) participants completed a follow-up questionnaire and of these, $101(86 \%)$ wore a UV dosimeter for 4 days and completed a sun diary. Of the 101 participants, we excluded 7 (6\%) from the analysis who had UV dosimeter data 
for weekdays only (missing weekend data). Thus the analysis dataset contained questionnaire, dosimeter and sun diary data for 94 (80\%) participants; of these 92 wore the dosimeters for two weekend days and two weekdays and two participants wore the dosimeters for one weekend day and three weekdays.

The total time spent outdoors each day was estimated from the questionnaire and sun diary records by summing the time spent outdoors for each hour of the day using the median values in each time period (e.g. 0-15 minute $=7.5$ minute). An average value was calculated separately for weekdays and weekends, as well as a daily average for the week ((weekday average $\times 5+$ weekend average $\times 2) / 7$ ).

UV exposure data were analysed using non-parametric methods due to its skewed nature. Descriptive statistics for continuous data were presented as median (interquartile range [IQR]). We assessed measures of agreement with respect to time spent outdoors between the UV dosimeter, questionnaire and sun diary at the 3-month follow-up using Spearman rank correlations $\left(\mathrm{r}_{\mathrm{s}}\right)$. Confidence intervals $(\mathrm{CI})$ were calculated using bias-corrected and accelerated (BCA) bootstrap methodology (19). The degree of correlation was rated as very weak $\left(\mathrm{r}_{\mathrm{s}}=0\right.$ $0.19)$, weak $\left(r_{\mathrm{s}}=0.2-0.39\right)$, moderate $\left(r_{\mathrm{s}}=0.40-0.59\right)$, strong $\left(\mathrm{r}_{\mathrm{s}}=0.60-0.79\right)$ or very strong $\left(\mathrm{r}_{\mathrm{s}}\right.$ $=0.8-1.0$ ) (20). We also assessed agreement between the questionnaire and sun diary using Bland-Altman (BA) plots, which plots the difference between the two measures against the mean of the measures for each participant, allowing visual examination of both random and systematic errors (21). We performed subgroup analyses to examine measures of agreement according to gender, age (18-44, 45-69 years) and employment status (full-time employed, other). We used Fisher's r-z transformation and the ZPF statistic (Fisher r-to-Z transformed rs) to test whether the correlation coefficients were statistically different between groups (22).

\section{RESULTS}

\section{Participant Characteristics}


Characteristics of the 94 participants are presented in Table 1. The ages of participants ranged from 22-69 years, with a mean age of 54 years (standard deviation [SD], 13 years). Over half $(53 \%)$ of the participants were university educated.

$<$ Table 1>

\section{Questionnaire, sun diary and dosimeter measure of sun exposure}

Questionnaire. Based on questionnaire responses, the median average time spent outdoors was 1.4 hours per day (h/day) (IQR 0.8-2.5) during weekdays and 2.5 h/day (IQR 1.5-3.3) during weekends. The weekly time spent outdoors was $1.7 \mathrm{~h} /$ day (IQR 1.1-2.4).

Sun diary. Based on diary responses, the median average time spent outdoors was $1.1 \mathrm{~h} / \mathrm{day}$ (IQR 0.6-1.8) during weekdays and $1.6 \mathrm{~h} / \mathrm{day}$ (IQR 0.9-2.8) during weekends. The weekly time spent outdoors was 1.4 h/day (IQR 0.8-1.9).

UV dosimeters. The median average weekly UV exposure was 0.6 SEDs per day (IQR 0.3-1.5) and there was a weak correlation between weekday and weekend exposure $\left(\mathrm{r}_{\mathrm{s}}=0.39,95 \% \mathrm{CI}\right.$ $0.23-0.52$ ) (Table 2). There was some evidence that the correlation between weekday and weekend exposure differed by employment status $(\mathrm{p}=0.05)$ and age group $(\mathrm{p}=0.05)$; weaker correlations were observed for participants in fulltime employment $\left(r_{s}=0.13,95 \%\right.$ CI -0.19 , 0.42) compared to other/non-employment $\left(\mathrm{r}_{\mathrm{s}}=0.53,95 \%\right.$ CI $\left.0.39,0.67\right)$; and for younger participants (18-44 years, $\mathrm{r}_{\mathrm{s}}=0.00,95 \% \mathrm{CI}-0.41,-0.35$ compared to older participants (45-69 years, $r_{s}=0.43,95 \%$ CI $\left.0.31,0.59\right)$. There was no evidence that correlations differed significantly by gender.

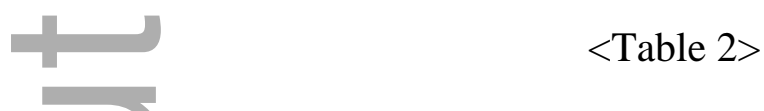

Correlations between questionnaire, sun diary and dosimeter measures. Table 3 presents the correlations between the questionnaire, sun diary and dosimeter measures of sun exposure. Strong correlations were observed between the dosimeter SEDs and the sun diary reports of time outdoors over the entire week (weekly $r_{s}=0.74$, CI 0.66, 0.81), on weekdays $\left(r_{s}=0.68\right.$, CI 0.57, $0.78)$ and weekends $\left(r_{s}=0.63\right.$, CI $\left.0.52,0.72\right)$. There was some evidence that the correlation between weekly dosimeter UV exposure and the sun diary reports of time outdoors differed 
according to age group, with those aged 18-44 years having a lower correlation $\left(\mathrm{r}_{\mathrm{s}}=0.48, \mathrm{CI}\right.$ $0.23,0.70)$ than those aged $45-69$ years $\left(r_{s}=0.77\right.$, CI $0.70,0.84, p$ for difference between correlations $=0.04)$.

The questionnaire measure of time spent outdoors was moderately correlated with dosimeter SEDs on weekdays $\left(\mathrm{r}_{\mathrm{s}}=0.55, \mathrm{CI} 0.42,0.67\right)$ and weekly $\left(\mathrm{r}_{\mathrm{s}}=0.57, \mathrm{CI}, 0.44,0.68\right)$ but weakly correlated with SEDs on weekends $\left(r_{s}=0.28\right.$, CI $\left.0.12,0.44\right)(p=0.01$ for difference between weekday and weekend correlations). Similarly, questionnaire measures were moderately correlated with sun diary measures on weekdays $\left(\mathrm{r}_{\mathrm{s}}=0.56, \mathrm{CI} 0.43,0.68\right)$ and weekly $\left(\mathrm{r}_{\mathrm{s}}=0.59\right.$, CI $0.48,0.68)$, but were weakly correlated for weekend data $\left(r_{s}=0.39\right.$, CI $\left.0.24,0.53\right)$. These correlations did not differ by gender or employment status subgroups, but there was weak evidence of a lower correlation among younger people $(\mathrm{p}=0.10)$.

<Table 3>

Bland-Altman agreement between self-report measure of time outdoors. The questionnaire overestimated the time spent outdoors compared to the sun diary on weekdays (median difference $0.2 \mathrm{~h} /$ day, CI -0.1, 0.5, p = 0.16); weekends (median difference 0.6 h/day, CI 0.3, 0.9, $\mathrm{p}=0.0002$ ) and weekly (median difference $0.3 \mathrm{~h} / \mathrm{day}$, CI $0.1,0.5, \mathrm{p}=0.01$ ). There was no evidence of systematic bias as the mean difference between sun diary and questionnaire measures was not correlated with time spent outdoors $(\mathrm{p}=0.26)$; however, there was more random variability in the differences between measures with greater time spent outdoors (Figure 2).

$<$ Figure 2>

\section{DISCUSSION}

Our findings indicate strong agreement between self-reported time spent outdoors recorded by a daily sun diary and objectively-measured UV exposure using UV dosimeters, and moderate agreement between questionnaire measures of 'usual' sun exposure and UV dosimeter SEDs. Other studies have found similar levels of agreement $(5,6,10,11,13-16)$. In Denmark, Koster et al (6) examined the correlations between UV dosimeter-measured SEDs, self-reported time spent 
outdoors using a short diary sent via a daily text message to participants' smartphones, and a longer retrospective questionnaire. They found strong correlations between the diary and the dosimeter SEDs on weekdays $\left(r_{\mathrm{s}}=0.67\right.$, CI 0.57, 0.74) and weekend days $\left(\mathrm{r}_{\mathrm{s}}=0.63\right.$, CI 0.45, 0.75), almost identical to our findings (on weekdays, $r_{s}=0.68$; on weekend days, $r_{s}=0.63$ ). Both our study and Koster et al's (6) study show stronger correlations between sun diary and UV dosimeter than that observed by Cargill et al (10), who reported moderate positive correlations between all three measures of diary, questionnaire and dosimeter in an Australian study of 47 older adults.

Lower agreement of UV dosimeters with questionnaires compared to sun diary measures is not surprising given that they were capturing slightly different constructs; the questionnaire was measuring usual sun exposure on a typical day over the past month, whereas the sun diary measure was capturing the exact same days as the dosimeter measure. Whilst correlation between the sun diary and dosimeter measures of UV exposure were similar for weekend and weekday exposures, the questionnaire had weaker agreement with dosimeter SEDs for weekend sun exposure. The questionnaire overestimated the time spent outdoors relative to the diary, consistent with other studies $(6,10,23,24)$, but we found this overestimation to be statistically significant only for weekend exposure. Other studies have reported poor agreement between questionnaire and sun diary for non-working compared to working days $(23,24)$. This may be due to participants having greater variability in their sun exposure habits on weekends, which may be more difficult to recall and capture on a questionnaire that is measuring usual sun exposure.

Agreement between dosimeter SEDs and the self-reported measures were also lower for younger participants (18-44 years) compared to older participants (45-69 years). It is likely that younger people have more variability in their sun habits, which may explain the lower agreement in this age-group. This theory is supported by our study's findings that younger participants and those in full-time employment had a very weak correlation between weekday and weekend SEDs, meaning that their sun exposure during the week was quite different to that over the weekend. O'Riordan et al (9) also found a weak correlation $\left(\mathrm{r}_{\mathrm{s}}=0.32\right)$ between sun diary and dosimeter over a four day period (including 2 weekend days) in an Australian cohort of younger 
participants (mothers with infants). Furthermore, a study in America by Chodick et al (23) showed greater variation in total time spent outdoors on weekends and a wider variety of recreational activities. These findings suggest that assessment of sun exposure may be more complex for weekends and for younger people, therefore to improve accuracy more detailed questionnaire measures and/or assessment over a greater number of weekend days may be required. Data from the physical activity literature suggest that 4 days of measurement is sufficient to capture 'usual' physical activity habits $(25,26)$. It would be useful to explore this further for sun exposure measurement, recognising that capturing 'usual' sun habits may be more challenging since sun habits are likely to differ between seasons and in places where the weather is more variable. Indeed, King et al. (24) found that including season and time of day in the questionnaire improved its reliability and accuracy, whilst lower agreements were associated with particular participant characteristics including being a current smoker, working outdoors, nonworking days, location of residence and summer and winter seasons.

Limitations of our study include a relatively small sample size recruited through a cancer research dedicated database; this may limit the generalizability to the wider population as the population sample was fairly well-educated and might have better compliance with wearing the dosimeters. Participants' knowledge that an objective measure of sun exposure was being used together with self-reported measures may have encouraged them to be more precise with their recall of self-reported sun exposure. The dosimeter and sun diary recorded all daylight hours, whereas the questionnaire only recorded exposure between $9 \mathrm{am}-5 \mathrm{pm}$, which may have led to a small degree of measurement error with the questionnaire data. We also did not capture other sun protection measures at different times of day that would allow adjustment of sun exposure for clothing worn or sunscreen use, nor were we able to assess the validity of self-reported sun protection measures, which are also important. Investigation of associations between sun exposure and health outcomes would also require collection of phenotype characteristics and sun exposure at different times of year including vacations. A novel aspect of our analyses was to examine differences in agreement between sun exposure measures according to different participant characteristics including age, gender and employment status. 
In conclusion, we found that both questionnaires and sun diaries provided valid measures of overall weekly sun exposure in our research population, with daily sun diaries demonstrating strong agreement and questionnaires having moderate agreement with UV dosimeter SEDs. Taken together with findings from other similar studies, our results suggest that questionnaires and sun diaries are suitable for population-level assessment of weekly sun exposure. Validity was lower for younger people and for questionnaire measures of weekend sun exposure, and correlation between weekend and weekday UV exposure was lower for people who were younger or in full-time employment. Suggestions for improving the accuracy of week-long sun exposure measurement for all population subgroups, which is a critical parameter for epidemiological studies of sun exposure and health, include using more detailed questionnaire measures over different seasons and holiday periods, or daily measurement over a longer period, and capturing specific participant characteristics such as type of employment, residential location, and clothing worn. Analysis of the validity of self-reported time outdoors at different periods of day, using time-stamped dosimeters as an objective reference measure, would also be useful for evaluation of sun protection strategies that aim to reduce peak-time UV exposure (11).

ACKNOWLEDGEMENTS: This study received funding from the Sydney Catalyst Translational Cancer Research Centre and The University of Sydney Cancer Strategic Priority Area for Research Collaboration (SPARC) Implementation Scheme. AE Cust received Career Development Fellowships from the National Health and Medical Research Council of Australia (NHMRC; 1063593) and Cancer Institute NSW (15/CDF/1-14). AK Smit received a Research Training Program (RTP) Stipend Scholarship and Merit Top Up Scholarship from the University of Sydney, and a Top Up Scholar Award from the Sydney Catalyst Translational Cancer Research Centre. MG Kimlin is supported through a Professorial Chair funding from Cancer Council Queensland.

\section{REFERENCES}


1. King L, Xiang F, Swaminathan A, Lucas RM. Measuring sun exposure in epidemiological studies: Matching the method to the research question. J Photochem Photobiol B. $2015 ; 153: 373-9$.

2. English D, editor Biological markers of skin damage. Cancer Forum; 1996: The Australian Cancer Society.

3. Karagas MR, Zens MS, Nelson HH, Mabuchi K, Perry AE, Stukel TA, Mott LA, Andrew AS, Applebaum KM, Linet M. Measures of Cumulative Exposure from a Standardized Sun Exposure History Questionnaire: A Comparison with Histologic Assessment of Solar Skin Damage. American Journal of Epidemiology. 2007;165(6):719-26.

4. Woolley T, Lowe J, Raasch B, Glasby M, Buttner PG. Workplace sun protection policies and employees' sun-related skin damage. American journal of health behavior. 2008;32:201-8. 5. Glanz K, Gies P, O'Riordan DL, Elliott T, Nehl E, McCarty F, Davis E. Validity of Selfreported Solar UVR Exposure Compared with Objectively Measured UVR Exposure. Cancer Epidemiology Biomarkers \& Prevention. 2010;19(12):3005-12.

6. Koster B, Sondergaard J, Nielsen JB, Allen M, Bjerregaard M, Olsen A, Bentzen J. Feasibility of smartphone diaries and personal dosimeters to quantitatively study exposure to ultraviolet radiation in a small national sample. Photodermatol Photoimmunol Photomed. 2015;31(5):252-60.

7. Mayer JA, Sallis JF, Eckhardt L, Creech L, Johnston MR, Elder JP, Lui KJ. Assessing children's ultraviolet radiation exposure: the use of parental recall via telephone interviews. American Journal of Public Health. 1997;87(6):1046-9.

8. O'Riordan DL, Lunde KB, Steffen AD, Maddock JE. Validity of beachgoers' self-report of their sun habits. Archives of dermatology. 2006;142(10):1304-11.

9. O'Riordan DL, Stanton WR, Eyeson-Annan M, Gies P, Roy C. Correlations between reported and measured ultraviolet radiation exposure of mothers and young children. Photochem Photobiol. 2000;71(1):60-4.

10. Cargill J, Lucas RM, Gies P, King K, Swaminathan A, Allen MW, Banks E. Validation of brief questionnaire measures of sun exposure and skin pigmentation against detailed and objective measures including vitamin D status. Photochem Photobiol. 2013;89(1):219-26. 
11. Koster B, Sondergaard J, Nielsen JB, Allen M, Olsen A, Bentzen J. The validated sun exposure questionnaire: association of objective and subjective measures of sun exposure in a Danish population-based sample. Br J Dermatol. 2017;176(2):446-56.

12. Sun J, Lucas RM, Harrison SL, van der Mei I, Whiteman DC, Mason R, Nowak M, Brodie AM, Kimlin MG. Measuring exposure to solar ultraviolet radiation using a dosimetric technique: understanding participant compliance issues. Photochem Photobiol. 2014;90(4):91924.

13. Chodick G, Kleinerman RA, Linet MS, Fears T, Kwok RK, Kimlin MG, Alexander BH, Freedman DM. Agreement between diary records of time spent outdoors and personal ultraviolet radiation dose measurements. Photochem Photobiol. 2008;84(3):713-8.

14. Dwyer T, Blizzard L, Gies PH, Ashbolt R, Roy C. Assessment of habitual sun exposure in adolescents via questionnaire--a comparison with objective measurement using polysulphone badges. Melanoma Res. 1996;6(3):231-9.

15. Sullivan SS, Cobb JL, Rosen CJ, Holick MF, Chen TC, Kimlin MG, Parisi AV. Assessment of sun exposure in adolescent girls using activity diaries. Nutrition Research. $2003 ; 23(5): 631-44$.

16. Thieden E, Ågren MS, Wulf HC. Solar UVR exposures of indoor workers in a Working and a Holiday Period assessed by personal dosimeters and sun exposure diaries.

Photodermatology, Photoimmunology \& Photomedicine. 2001;17(6):249-55.

17. Smit AK, Espinoza D, Newson AJ, Morton RL, Fenton G, Freeman L, Dunlop K, Butow PN, Law MH, Kimlin MG, Keogh LA, Dobbinson SJ, Kirk J, Kanetsky PA, Mann GJ, Cust AE. A Pilot Randomized Controlled Trial of the Feasibility, Acceptability, and Impact of Giving Information on Personalized Genomic Risk of Melanoma to the Public. Cancer Epidemiol Biomarkers Prev. 2017;26(2):212-21.

18. Thieden E, Agren MS, Wulf HC. The wrist is a reliable body site for personal dosimetry of ultraviolet radiation. Photodermatol Photoimmunol Photomed. 2000;16(2):57-61.

19. Chan W, Chan DW. Bootstrap standard error and confidence intervals for the correlation corrected for range restriction: a simulation study. Psychol Methods. 2004;9(3):369-85.

20. O'Donnell B. Statistics at Square One. British Medical Journal. 1977;1(6058):451-.

21. Martin Bland J, Altman D, G. Statistaical Methods For Assessing Agreement Between Two Methods of Clinical Measurement The Lancet. 1986;327(8476):307-10. 
22. Raghunathan TE, Rosenthal R, Rubin DB. Comparing correlated but nonoverlapping correlations. Psychological Methods. 1996;1(2):178-83.

23. Chodick G, Freedman MD, Kwok RK, Fears TR, Linet MS, Alexander BH, Kleinerman RA. Agreement Between Contemporaneously Recorded and Subsequently Recalled Time Spent Outdoors: Implications for Environmental Exposure Studies. Annals of Epidemiology. 2007;17(2):106-11.

24. King L, Xiang F, Swaminathan A, Dear K, Harrison SL, van der Mei I, Kimlin MG, D'Este C, Lucas RM. Validation of Sun Exposure Reported Annually Against Interim Self-report and Daily Sun Diaries. Photochemistry and Photobiology. 2017;93(5):1294-302.

25. Hart TL, Swartz AM, Cashin SE, Strath SJ. How many days of monitoring predict physical activity and sedentary behaviour in older adults? The International Journal of Behavioral Nutrition and Physical Activity. 2011;8:62-.

26. Tudor-Locke C, Burkett L, Reis JP, Ainsworth BE, Macera CA, Wilson DK. How many days of pedometer monitoring predict weekly physical activity in adults? Preventive Medicine. 2005;40(3):293-8.

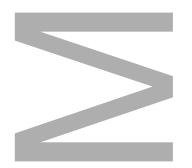

Table 1. Descriptive characteristics of participants.

\begin{tabular}{lcc}
\hline Age & $\mathrm{N}=94$ & Mean or $\%$ \\
18-44 years & 94 & 53.7 (SD 13.4) \\
44-69 years & 25 & $26 \%$ \\
Gender & 69 & $73 \%$ \\
Female & & \\
Male & 48 & $51 \%$ \\
Highest level of education & 46 & $49 \%$ \\
$\quad$ High school (or equivalent) & 13 & $14 \%$ \\
Trade/diploma & 31 & $33 \%$
\end{tabular}


University degree or higher $\quad 50 \quad 53 \%$

Genomic risk category

\begin{tabular}{lcc} 
Low & 25 & $27 \%$ \\
Average & 45 & $48 \%$ \\
High & 24 & $26 \%$ \\
SEDs (h/day) & & Median (IQR) \\
Weekday & 94 & $0.5(0.2-1.5)$ \\
Weekend & 94 & $0.5(0.2-1.2)$ \\
Weekly & 94 & $0.6(0.3-1.5)$ \\
Sun Diary (h/day) & & \\
Weekday & 94 & $1.1(0.6-1.8)$ \\
Weekend & 94 & $1.6(0.9-2.8)$ \\
Weekly & 94 & $1.4(0.8-1.9)$ \\
Questionnaire (h/day) & & \\
Weekday & 94 & $1.4(0.8-2.5)$ \\
Weekend & 94 & $2.5(1.5-3.3)$ \\
Weekly & 94 & $1.7(1.1-2.4)$ \\
\hline
\end{tabular}

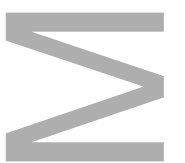

Table 2. Spearman rank correlations between weekend and weekday UV exposure measured as standard erythemal doses (SEDs) by the UV dosimeters.

\begin{tabular}{llccc}
\hline $\mathbf{N}$ & $\mathbf{r}_{\mathrm{s}}$ & $\mathbf{9 5 \%} \mathbf{C I}$ & P-value $^{1}$ \\
SEDs weekdays vs & 94 & 0.39 & $(0.23,0.52)$ & \\
weekends & & & & \\
Gender & & & & \\
Women & 48 & 0.23 & $(-.04,0.46)$ & 0.51 \\
Men & 46 & 0.36 & $(0.16,0.56)$ & \\
Employment & & & & \\
Fulltime employment & 31 & 0.13 & $(-.19,0.42)$ & 0.05 \\
$\quad$ Other employment & 63 & 0.53 & $(0.39,0.67)$ & \\
Age & & & & 0.05 \\
18-44 years & 25 & 0.00 & $(-.41,0.35)$ & \\
44-69 years & 69 & 0.46 & $(0.31,0.59)$ & \\
\hline
\end{tabular}


CI, confidence interval

${ }^{1} \mathrm{P}$-value for difference in correlations between subgroups

Table 3. Spearman rank correlations between questionnaire, diary and dosimeter measures of sun exposure.

\begin{tabular}{lllll}
\hline $\mathbf{N}$ & $\mathbf{r}_{\mathrm{s}}$ & $\mathbf{9 5 \%} \mathbf{C I}$ & P-value $^{\mathbf{1}}$ \\
$\begin{array}{l}\text { Diary vs dosimeter } \\
\text { Weekly }\end{array}$ & 94 & 0.74 & $(0.66,0.81)$ & \\
Day type & & & & \\
Weekday & 94 & 0.68 & $(0.57,0.78)$ & 0.59 \\
Weekend & 94 & 0.63 & $(0.52,0.72)$ & \\
Gender & & & & \\
Women & 48 & 0.56 & $(0.37,0.73)$ & 0.10 \\
Men & 46 & 0.76 & $(0.64,0.84)$ & \\
Employment & 31 & & & 0.21 \\
Fulltime employment & 63 & 0.63 & $(0.42,0.82)$ & \\
Other employment & & 0.77 & $(0.67,0.84)$ & \\
Age & 25 & 0.48 & $(0.23,0.70)$ & 0.04 \\
18-44 years & 69 & 0.77 & $(0.70,0.84)$ & \\
44-69 years & & &
\end{tabular}

\section{Questionnaire vs dosimeter \\ Weekly}

$(0.44,0.68)$

Day type

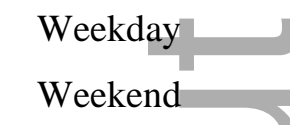

$(0.42,0.67)$

94

0.28

$(0.12,0.44)$

0.01

\section{Gender}

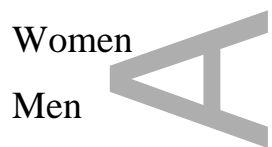

\section{Employment}

Fulltime employment

Other employment

$\begin{array}{lll}48 & 0.34 & (0.10,0.55) \\ 46 & 0.59 & (0.40,0.75)\end{array}$

0.13

31

63

0.55

$(0.27,0.77)$

0.52

$(0.36,0.66)$

0.86 


\section{Age}
18-44 years
25
0.28
$(-.08,0.62)$
44-69 years
69
0.60
$(0.46,0.72)$
0.10

\section{Diary vs Questionnaire}

$\begin{array}{lcccc}\text { Weekly } & 94 & 0.59 & (0.48,0.68) & \\ \text { Day type } & 94 & 0.56 & (0.43,0.68) & 0.12 \\ \text { Weekday } & 94 & 0.39 & (0.24,0.53) & \\ \text { Weekend } & & & \\ \text { Gender } & 48 & 0.48 & (0.27,0.65) & 0.65 \\ \text { Women } & 46 & 0.55 & (0.37,0.69) & \\ \text { Men } & & & (0.30,0.82) & \\ \text { Employment } & 31 & 0.57 & (0.39,0.66) & \\ \text { Fulltime employment } & 63 & 0.53 & & \\ \text { Other employment } & & & (0.38,0.79) & 0.62 \\ \text { Age } & 25 & 0.64 & (0.43,0.66) & \\ \text { 18-44 years } & 69 & 0.56 & \\ \text { 44-69 years } & & & \end{array}$

CI, confidence interval

${ }^{1} \mathrm{P}$-value for difference in correlations between subgroups

\section{FIGURE CAPTIONS}

Figure 1. Study Flowchart.

Figure 2. Bland-Altman plot of the difference between diary and questionnaire responses of average weekly time outdoors. 


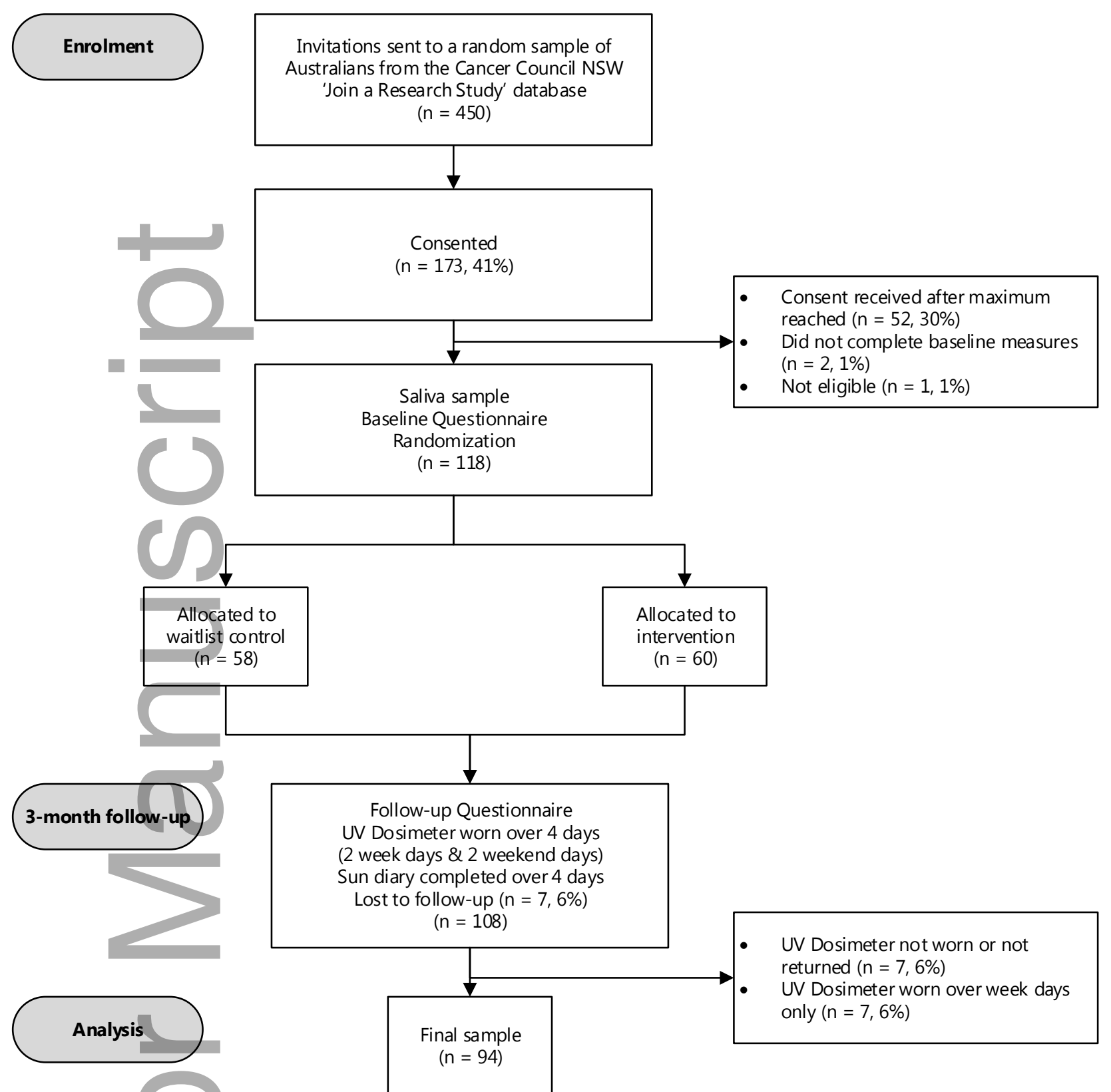




\section{Diary V Questionnaire weekly (hrs/day)}

Difference vers us mean (with mean diffe rence and +/- 1.96SD).

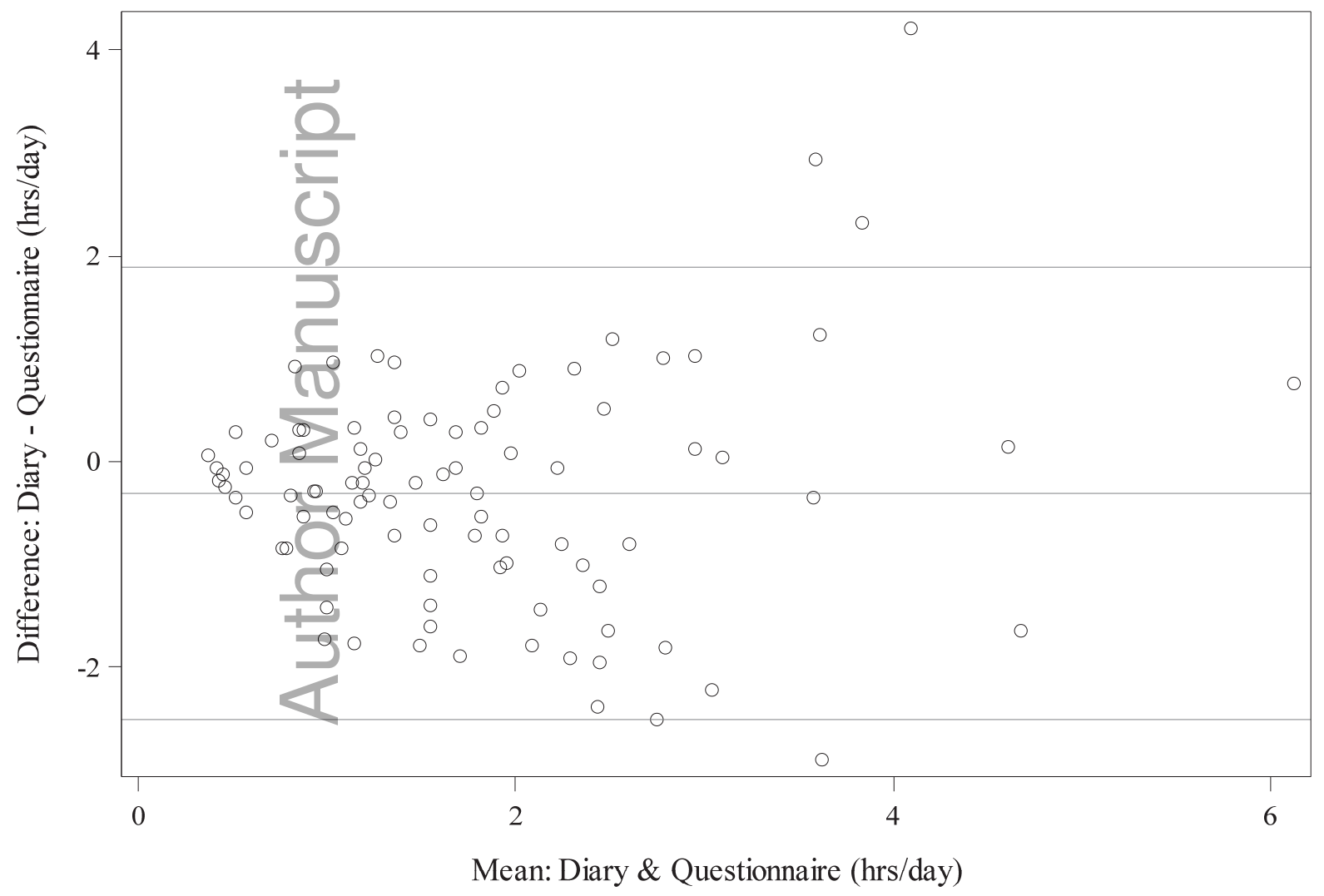




\section{University Library}

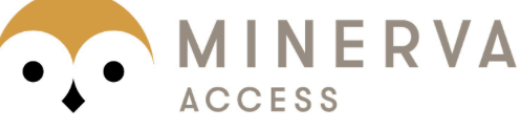

A gateway to Melbourne's research publications

Minerva Access is the Institutional Repository of The University of Melbourne

Author/s:

Cust, AE;Fenton, GL;Smit, AK;Espinoza, D;Dobbinson, S;Brodie, A;Dang, HTC;Kimlin, MG

Title:

Validation of Questionnaire and Diary Measures of Time Outdoors Against an Objective Measure of Personal Ultraviolet Radiation Exposure.

Date:

2018-07

\section{Citation:}

Cust, A. E., Fenton, G. L., Smit, A. K., Espinoza, D., Dobbinson, S., Brodie, A., Dang, H. T. C. \& Kimlin, M. G. (2018). Validation of Questionnaire and Diary Measures of Time Outdoors Against an Objective Measure of Personal Ultraviolet Radiation Exposure.. Photochem Photobiol, 94 (4), pp.815-820. https://doi.org/10.1111/php.12893.

Persistent Link:

http://hdl.handle.net/11343/283854 